\section{Pulmonary anthracosis in Dhaka Zoo collections - a public health forecasting for city dwellers}

\author{
S.A. Ahasan ${ }^{1}$, E.H. Chowdhury ${ }^{2}$, S.U. Azam ${ }^{3}$, \\ R. Parvin ${ }^{2}$, A.Z. Rahaman ${ }^{3}$ \& A.R. Bhuyan ${ }^{3}$
}

${ }^{1,3}$ Department of Livestock Services, Research Section, Dhaka Zoo, Mirpur-1, Dhaka 1216, Bangladesh

${ }^{2}$ Department of Pathology, Faculty of Veterinary Science,

Bangladesh Agricultural University, Mymensingh 2202,

Bangladesh

Email: ${ }^{1}$ ahasan67@gmail.com

Anthracosis is the deposition of carbon particles or industrial dusts in the lungs (Manohar et al. 2006). The condition is frequent in animals reared in cities especially in dusty or smoky industrial and construction areas. People working in coal mines as well as animals, particularly dogs, horses and mules reared in the vicinity are considered to be at high risk of anthracosis (Runnels 1960; Jubb \& Kennedy 1985; Jubb et al. 1993; Jones \& Hunt 1983, 1997). The lungs and associated lymph nodes preserve inhaled particles that also get lodged in connective tissue in inter alveolar septae, mononuclear phagocytes and epithelial tissue found freely suspended in bronchioles and alveoli (Sujatha et al. 2007). Reports on the occurrence of anthracosis in a variety of domestic animals are available while reports on the occurrence of the disease in captive wild animals are sparse (Manohar et al. 2006; Sujatha et al. 2007). Dhaka Zoo is situated amidst brick kilns, dusty roads and construction activities. Necropsy lesions in particular black discoloration of lung

Date of publication (online): 26 October 2010

Date of publication (print): 26 October 2010

ISSN 0974-7907 (online) I 0974-7893 (print)

Editor: Ulrike Streicher

Manuscript details:

Ms \# 02334

Received 20 October 2009

Final revised received 08 September 2010

Finally accepted 24 September 2010

Citation: Ahasan, S.A., E.H. Chowdhury, S.U. Azam, R. Parvin, A.Z. Rahaman \& A.R. Bhuyan (2010). Pulmonary anthracosis in Dhaka Zoo collections - a public health forecasting for city dwellers. Journal of Threatened Taxa 2(11): 1303-1308.

Copyright: (c) S.A. Ahasan, E.H. Chowdhury, S.U. Azam, R. Parvin, A.Z. Rahaman \& A.R. Bhuyan 2010. Creative Commons Attribution 3.0 Unported License. JoTT allows unrestricted use of this article in any medium for non-profit purposes, reproduction and distribution by providing adequate credit to the authors and the source of publication.

Acknowledgements: The authors are really indebted to both the authority of Dhaka Zoo and the Department of Pathology, FVS, BAU, Mymensingh, Bangladesh.

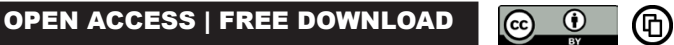

parenchyma inspired this study with emphasis on anthracosis.

Materials and Methods: A total of 36 animals of 24 different species from Dhaka Zoo were investigated in this study between 01 May 2007 and 31 May 2009 (Table 1).

Dhaka Zoo is situated $20 \mathrm{~km}$ off from Dhaka central point in Mirpur. The zoo is located in a scenic landscape by the side of the river Turag and attracts many visitors. On the other hand, busy roads and construction activities around the zoo make this location very dusty.

Birds, non-human primates and other small animals in Dhaka Zoo are housed in sheds, with roofs of corrugated galvanized iron (GI ) sheets, concrete floor and wire netting on all four sides. The average height of the sheds of the study animals is $4 \mathrm{~m}$ from the plinth level. Antelopes are kept in open sky large enclosures while small animals such as reptiles are housed in very small box-shaped glass chambers with GI roofing and concrete floors.

The samples were examined out of a total of 127 Rhesus Macaques, 180 Spotted Deer, 11 Golden Pheasants, Six Striped Hyena, 14 Asiatic Lions, five Goyals, three American Rhea, 11 Australian Terrier Dogs, three Zebras, seven Nilgais, three Horses, four Barking Deer, two ostriches, six Crested Serpent-eagles, seven common langurs, two Beisa Oryx and two Olive Baboons.

Necropsy and tissue processing: Necropsies were conducted immediately following the death of sampled animals. Nodulations, discolorations and unnatural consistencies were noted incase of lungs. Tissue samples of all 36 lungs $(4 \times 4 \mathrm{~cm})$ were preserved in $10 \%$ neutral buffered formalin. The fixed tissue samples were sent to the Department of Pathology, Faculty of Veterinary Science, Bangladesh Agricultural University, Mymensingh, for detailed investigation, where tissues were trimmed, processed, sectioned $(5 \mu \mathrm{m})$ and stained as per standard procedure of H\&E (Luna 1968).

Results: Necropsy revealed minute to large black spots to blackish discoloration of the examined tissue samples with yellow-white caseous nodules in 27 out of 36 samples. Tissue changes were also noted as both white nodular areas and black spots, and relatively firm consistency of lung stroma in scattered fashion along with aggregation of brownish-black carbon particles in the lung parenchyma in association with greenish color infrequently (Images 1-10). Histopathology revealed carbon deposition to be associated with congestion and / or hemorrhages, and infrequently with infiltration of mononuclear cells and fibrosis (scars) sometimes with collapsed alveoli. On histopathology, all 27 samples showed aggregation of carbon particles in the lung parenchyma in epithelial cells, in connective tissue of alveolar septa, inside granuloma and in mononuclear 
Table 1. Positive cases of anthracosis

\begin{tabular}{|c|c|c|c|c|}
\hline & Sampled animal & Date of necropsy & Age and sex & Remarks \\
\hline 1 & Rhesus Macaque (Macaca mulatta) & 29.iv.2007 & $10 \mathrm{y}$, Male & Anthracosis \\
\hline 2 & Rhesus Macaque & 07.vii.2007 & $8 \mathrm{y}$, Female & Anthracosis \\
\hline 3 & Rhesus Macaque & 18.xi.2007 & $12 \mathrm{y}$, Male & Anthracosis \\
\hline 4 & Rhesus Macaque & 11.xii.2007 & $12 \mathrm{y}$, Female & Anthracosis \\
\hline 5 & Rhesus Macaque & 11.xii.2007 & 4 y, Female & Anthracosis \\
\hline 6 & Rhesus Macaque & 13.iii.2008 & $8 \mathrm{y}$, Male & Anthracosis \\
\hline 7 & Rhesus Macaque & 21.xii.2008 & $4 \mathrm{y}$, Male & Anthracosis \\
\hline 8 & Spotted Deer (Axis axis) & 01.v.2007 & $10 \mathrm{y}$, Male & Anthracosis \\
\hline 9 & Spotted Deer & 22.xi.2007 & $8 \mathrm{y}$, Male & Anthracosis \\
\hline 10 & Spotted Deer & 29.xii.2007 & $13 \mathrm{y}$, Male & Anthracosis \\
\hline 11 & Spotted Deer & 10.ii.2008 & $2 \mathrm{~m}$, Female & Anthracosis \\
\hline 12 & Golden Pheasant (Chrysolophus pictus) & 23.xi.2007 & $4 \mathrm{y}$, Male & Anthracosis \\
\hline 13 & Golden Pheasant & 27.ii.2008 & 6 y, Male & Anthracosis \\
\hline 14 & Striped Hyena (Hyena hyena) & 13.v.2007 & 23 y, Female & Anthracosis \\
\hline 15 & Asiatic/Indian Lion (Panthera leo persica) & 17.v.2007 & $16 \mathrm{y}$, Male & Anthracosis \\
\hline 16 & Gayal (Bos frontalis) & 25.vii. 2007 & $18 \mathrm{y}$, Male & Anthracosis \\
\hline 17 & American Rhea (Rhea americana) & 05.viii.2007 & $8 y$, Female & Anthracosis \\
\hline 18 & Australian Terrier Dog (Canis lupus familiarizes) & 07.ix.2007 & $12 \mathrm{y}$, Male & Anthracosis \\
\hline 19 & Zebra (Equus zebra hartmannae) & 09.x.2007 & $10 \mathrm{y}$, Female & Anthracosis \\
\hline 20 & Nilgai (Boselaphus tragocamelus) & $25 . x .2007$ & $10 \mathrm{y}$, Female & Anthracosis \\
\hline 21 & Horse (Equus caballus) & 27.xii.2007 & 24 y, Female & Anthracosis \\
\hline 22 & Barking Deer (Muntiacus muntjak) & 27.xii.2007 & $5 y$, Female & Anthracosis \\
\hline 23 & Ostrich (Struthio camelus) & 16.i.2008 & 9 y, Female & Anthracosis \\
\hline 24 & Crested Serpent-eagle (Spilorins cheela) & 26.i.2008 & 16 y, Female & Anthracosis \\
\hline 25 & Common Langur (Presbytis entellus) & 31.i.2008 & $7 y$, Female & Anthracosis \\
\hline 26 & Beisa Oryx (Oryx beisa beisa) & 15.vii.2008 & $17 \mathrm{~m}$, Female & Anthracosis \\
\hline 27 & Olive Baboon (Papio anubis) & 22.xii.2008 & $12 \mathrm{y}$, Male & Anthracosis \\
\hline
\end{tabular}

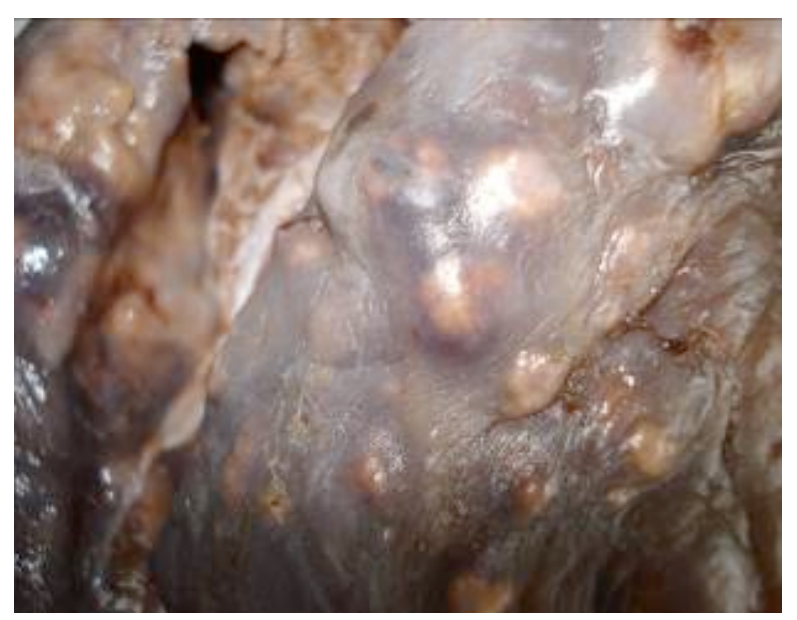

Image 1. Lung of Spotted Deer showing caseous nodules and black-brown coloration

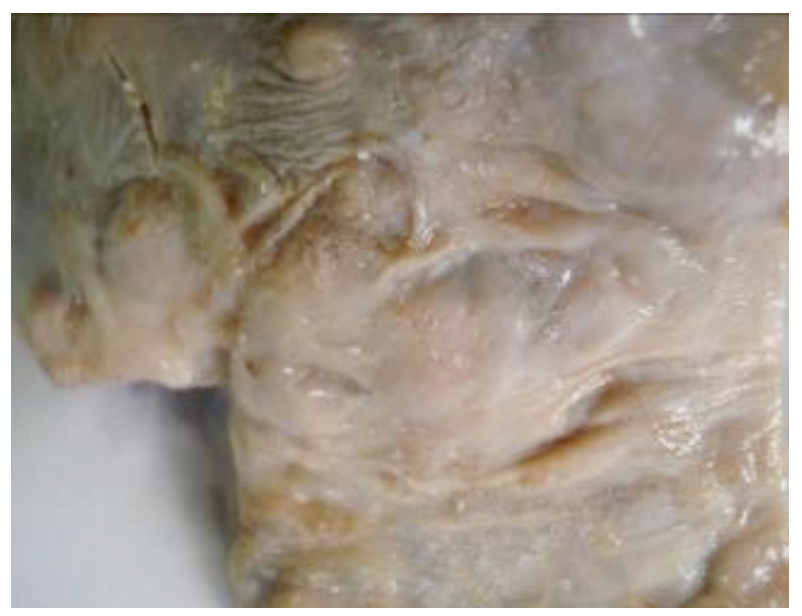

Image 2. Lung of Rhesus Macaque showing caseous nodules and blackish-green coloration 


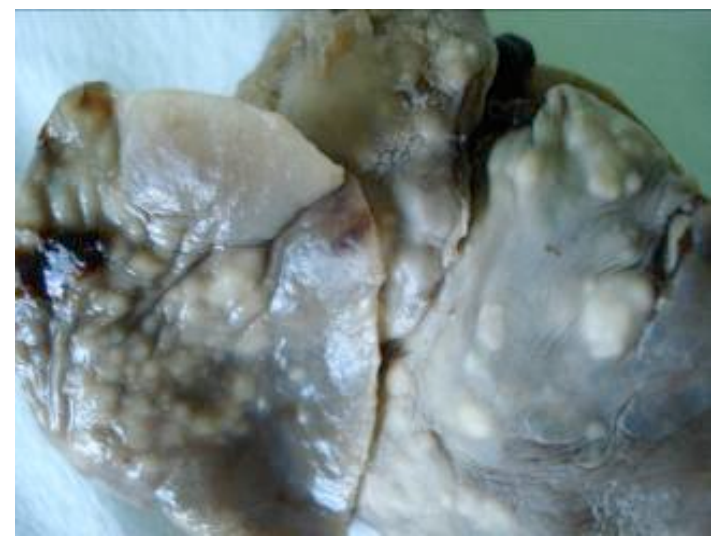

Image 3. Lung of Rhesus Macaque showing white caseous nodules and black-brown coloration

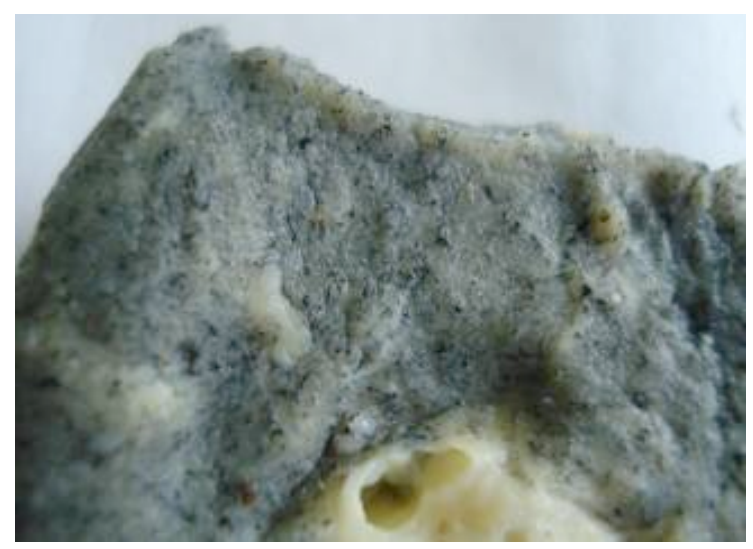

Image 5. Lung of Striped Hyena showing minute nodules and numerous black clumps coloration all over parenchyma

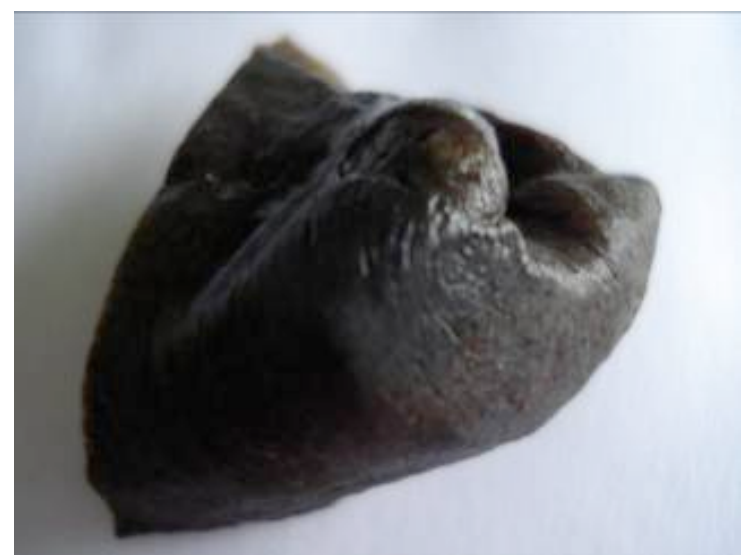

Image 7. Lung of Terrier dog showing massive black-brown coloration throughout the parenchyma

cells (Images 11-18). Carbon particles were found lodged intracellular in epithelial cells, mononuclear cells and granuloma while extracellular in alveolar septae and lung parenchyma. Free carbon particles were also found

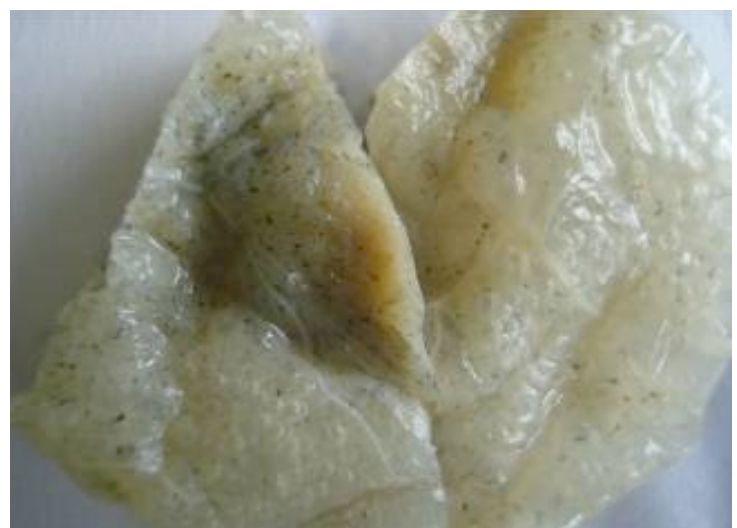

Image 4. Lung of Indian Lion showing pale and clumps of black coloration all over the parenchyma

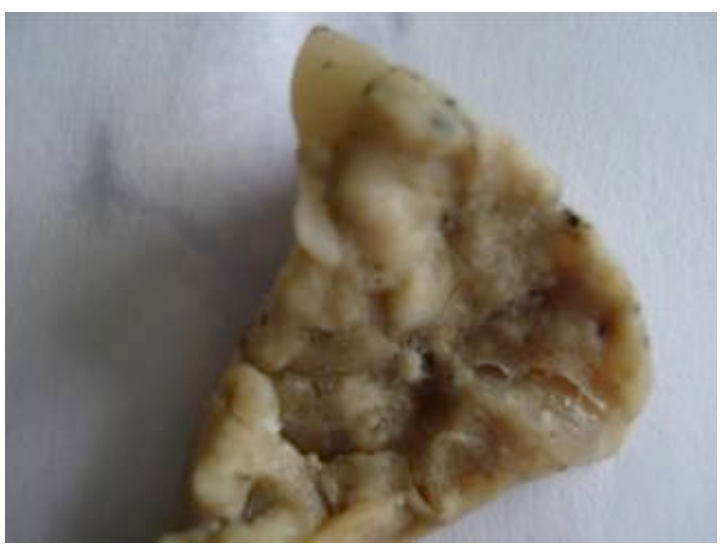

Image 6. Lung of Gayal showing caseous nodules and black-brown coloration

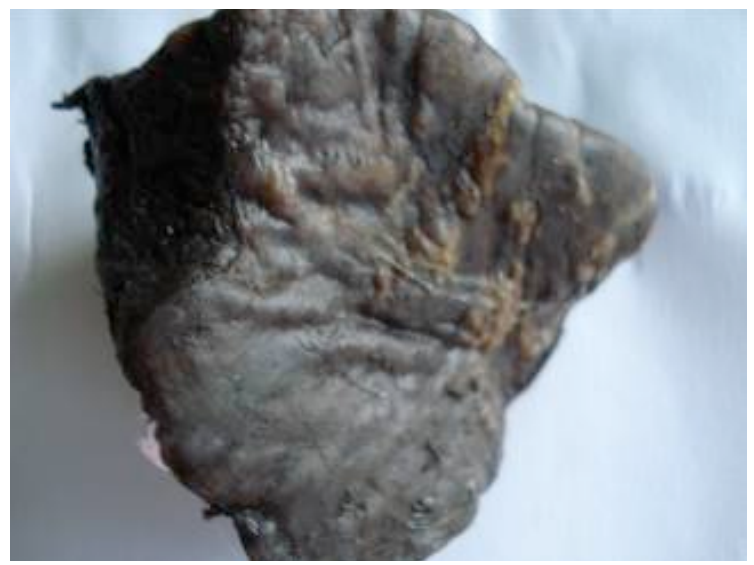

Image 8. Lung of Zebra showing caseous nodules and black-brown coloration all over the parenchyma

in bronchioles and alveoli. Clumping of carbon particles was found frequently associated with congestion and hemorrhages while less frequently with inflammation, collapsed alveoli and fibrous scars. Animals newly arrived 


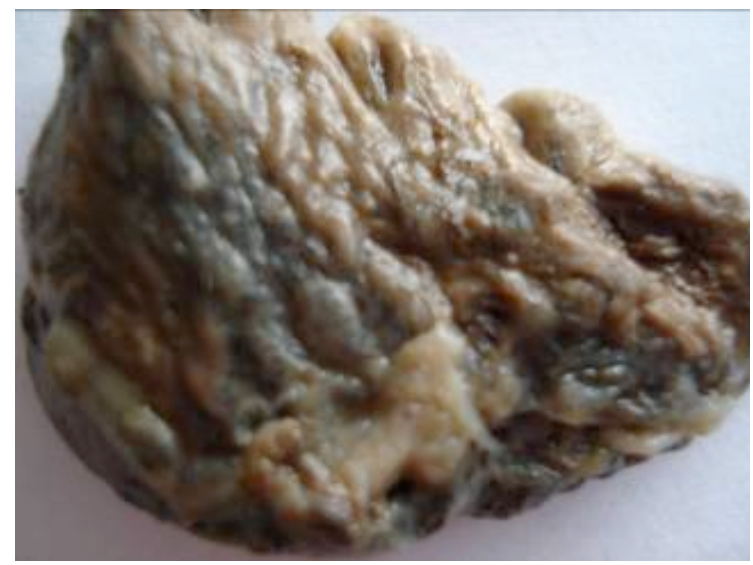

Image 9. Lung of Golden Pheasant showing caseous nodules and black-brown with greenish-black coloration all over

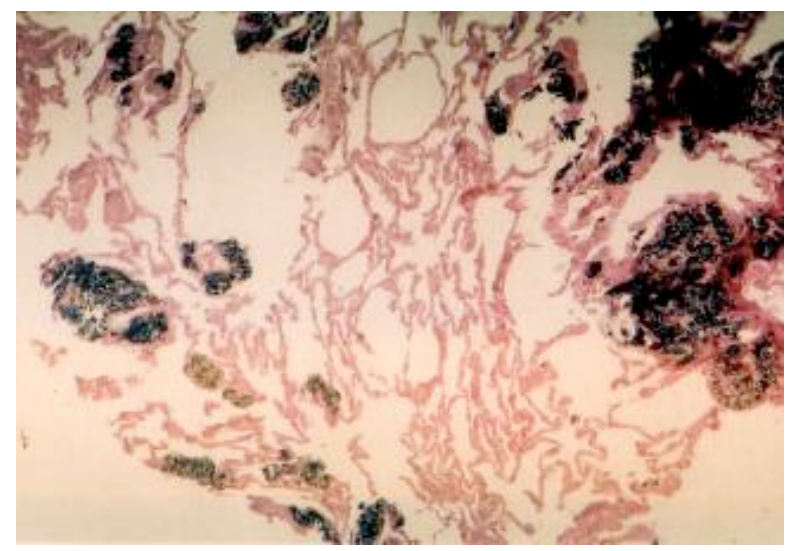

Image 11. Lung of Rhesus Macaque showing granuloma, deposition of carbon particles, Anthracosis, H\&E, 87.5x.

in Dhaka Zoo, aged less than one year and reptiles showed no carbon deposition in lungs (Fig. 1).

Discussion and Conclusions: Macroscopic necropsy findings of this study are similar to findings of other studies on anthracosis in wild animals (Farrow 1975; Gupta et al. 1991; Manohar et al. 2006; Sujatha et al. 2007) and in domestic animals (Jubb et al. 1993; Jones et al. 1997). Also, histopathological findings were mostly consistent with the findings of other authors (Manohar et al. 2006; Sujatha et al. 2007). Only the fibrosis we occasionally found in our study has not been reported previously in association with anthracosis in wild animals. Differences were also found in the size of the carbon particles as compared to minute particle sizes reported by Farrow (1975) in dog, Yu-Tong et al. (1984) in felines from circus, Gupta et al. (1991) in leaf monkey, Manohar et al. (2006) and Sujatha et al. (2007) in large wild felids. The size of the carbon particle found in our study are partly minute (dotted) but we also found large particles (Spreading), which have not been reported before. However, the distribution of the carbon particles

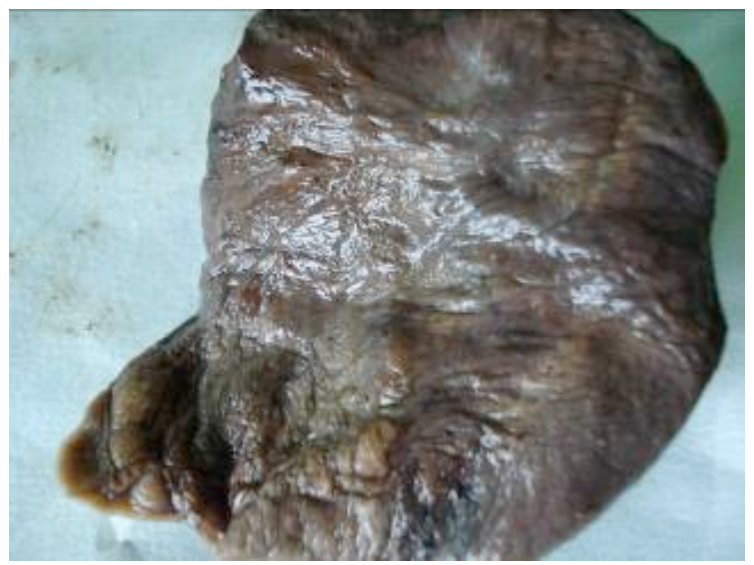

Image 10. Lung of Beisa Oryx showing caseous nodules and black-brown coloration all over

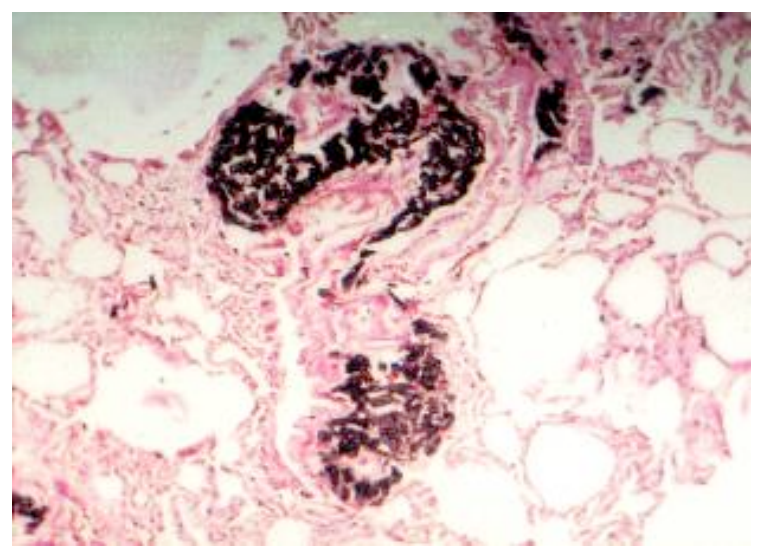

Image 12. Lung of Striped hyena showing granuloma and deposition of carbon particles, Anthracosis, H\&E, 100x.

was found to be similar. This is the first comprehensive overview on anthracosis in an animal collection. Thirty-six individuals of 24 different species from the same location were included in contrast to other works where only single or very few cases were described. This study ensures occurrence of anthracosis in majority of animals of Dhaka Zoo as a consequence of alarming rate of air pollution prevalent in the city whilst other studies limit the findings to a few study animals and do not give the effects on a range of animals. Present study also indicative of possible development of cancerous or fatal consequences which needs yet to be further research.

Smokes and dust from city traffic, nearby brick fields, industries and leaf burning appear to cause anthracosis in Dhaka Zoo animals. The macroscopic necropsy findings and histopathological findings in the lungs of Dhaka Zoo animals suggest that similar lesions may be present in humans. Selim (2008) has reported that traffic policemen who were worst exposed to dust and smokes, suffer from respiratory distress, coughing, chest pain, asthma, high blood pressure, indigestion, jaundice, skin diseases, 


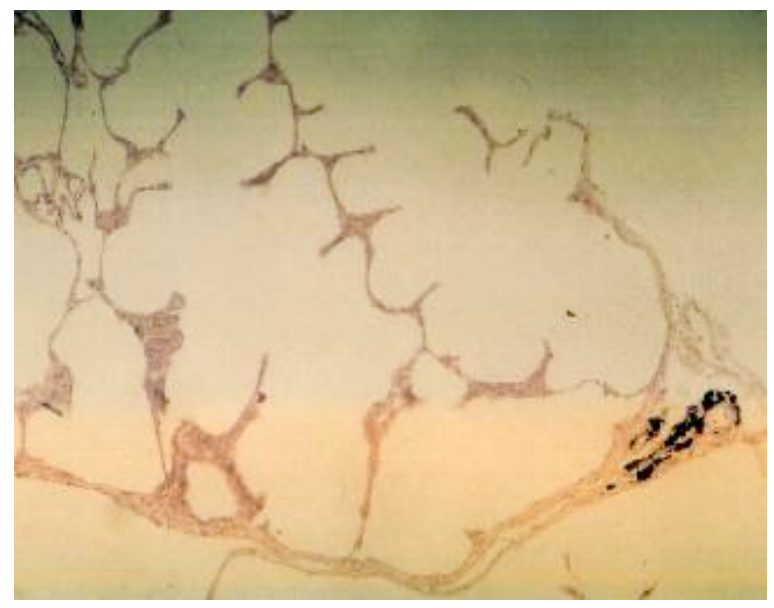

Image 13. Lung of Gayal showing granuloma and deposition of carbon particles, Anthracosis, H\&E, 87.5x.

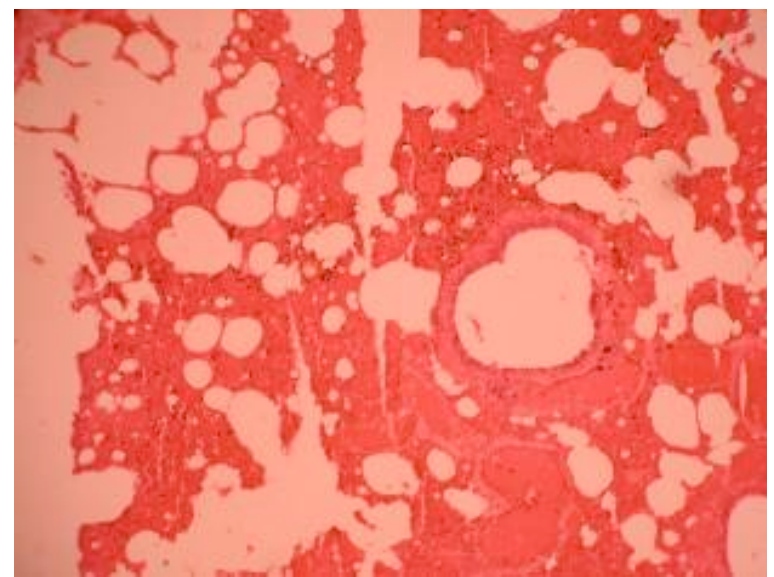

Image 15. Lung of Zebra showing deposition of carbon particles, collapsed alveoli and congestion, Anthracosis, H\&E, 100x.

heart diseases and osteoarthritis among other clinical signs as result of dust and smoke borne ailment and are frequently admitted to the Central Police Hospital with respiratory problems. Selim also described members of the traffic police as more prone to chronic diseases than other police personnel; they make up the majority of patients at the Central Police Hospital in Dhaka and have unexpectedly short life spans. Examination of lungs of other permanent city residents is urgently recommended. Many ordinary city residents may be equally exposed to dusts and smoke as the Dhaka Zoo animals. The dusts may contain mineral particles including carbon, aluminum and calcium salts (non-silicates) and silicates that predispose cancer (Yu-Tong et al. 1983). Other than soil borne dust particles, all metallic and chemical borne dust particles influence both quality and quantity of cancer.

Detailed analysis of the physical and chemical properties of the particles frequent in Dhaka City, particularly from industrial and construction areas, is

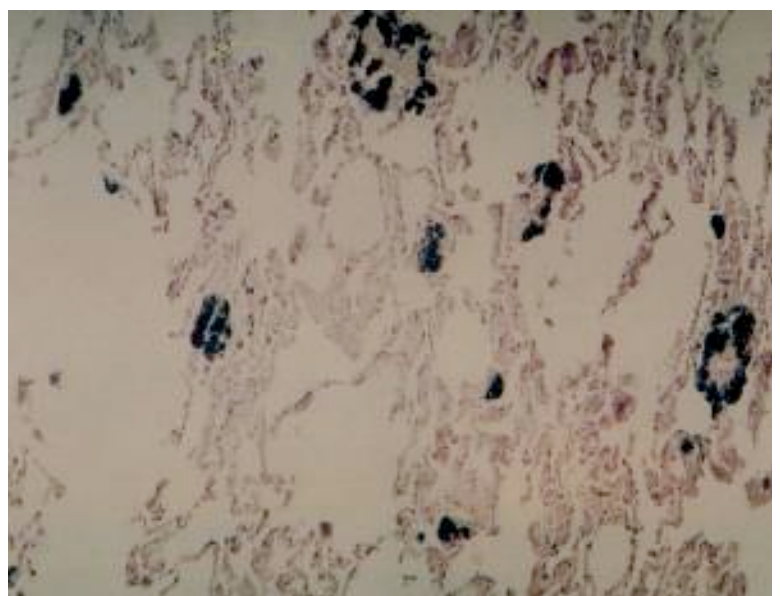

Image 14. Lung of Indian lion showing deposition of carbon particles, Anthracosis, H\&E, 87.5x.

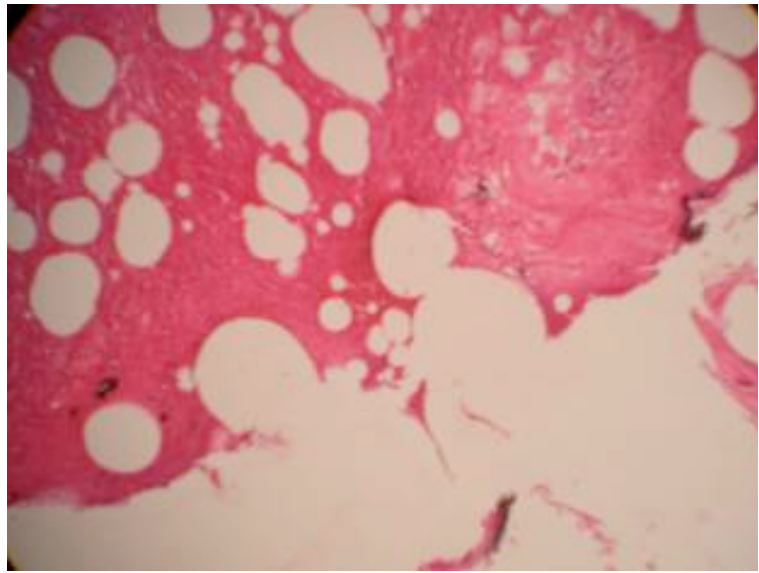

Image 16. Lung of Beisa oryx showing deposition of carbon particles, granuloma and collapsed alveoli, Anthracosis, H\&E, 100x.

strongly recommended. Special attention needs to be paid to minimize the dust and smokes thereby reducing the risks both for zoo animals and people living in Dhaka.

\section{REFERENCES}

Farrow, C.S. (1975). Smoke inhalation in the current concepts of pathophysiology and management. Veterinary Medicine and Small Animal Clinician 70: 406-414.

Gupta, V.K. \& R.C. Katoch (1991). Pulmonary anthracosis in dog: a case report. Indian Journal of Veterinary Pathology 15(1): 47.

Jones C.J. \& R.D. Hunt (eds.) (1983). Veterinary Pathology. $5^{\text {th }}$ edition. Lea \& Febiger, Philadelphia, USA, v+56pp.

Jones, T.C., R.D. Hunt \& N.W. King (eds.) (1997). Veterinary Pathology. 6th edition. Williams \& Wilkins, Baltimore, $\mathrm{v}+62 \mathrm{pp}$.

Jubb, K.V., P.C. Kennedy \& N. Palmer (1985). Pathology of Domestic Animals. Vol. 2, $3^{\text {rd }}$ edition. Academic Press, Inc., London, vii+219pp.

Jubb, K.V., P.C. Kennedy \& N. Palmer (1993). Pathology of 


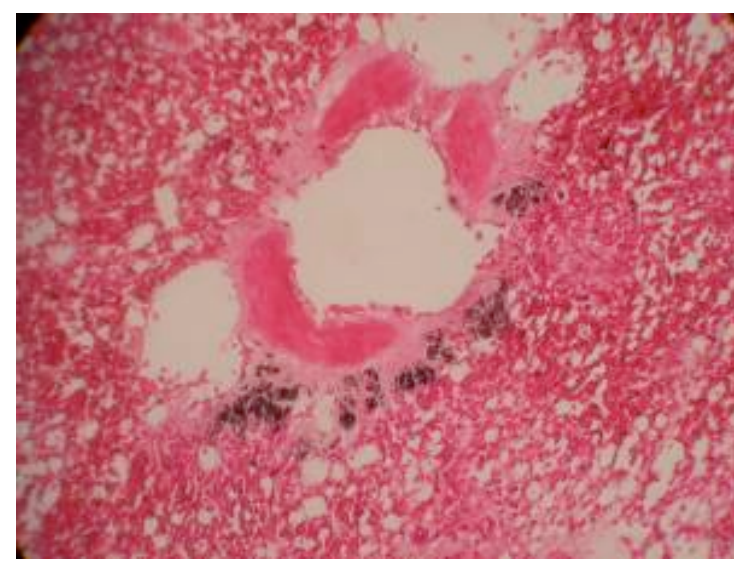

Image 17. Lung of Rhea showing deposition of carbon particles, congestion and collapsed alveoli, Anthracosis, H\&E, 200x.

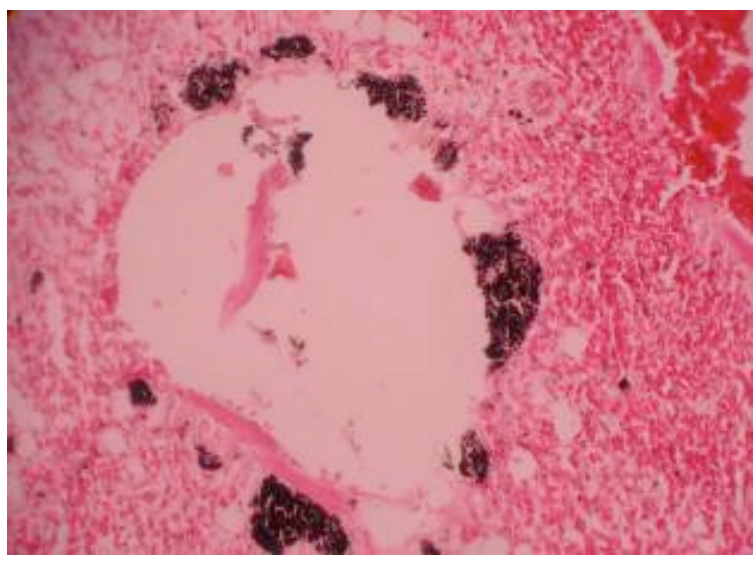

Image 18. Lung of Golden Pheasant showing deposition of carbon particles, congestion and fibrosis, Anthracosis, H\&E, 200x.

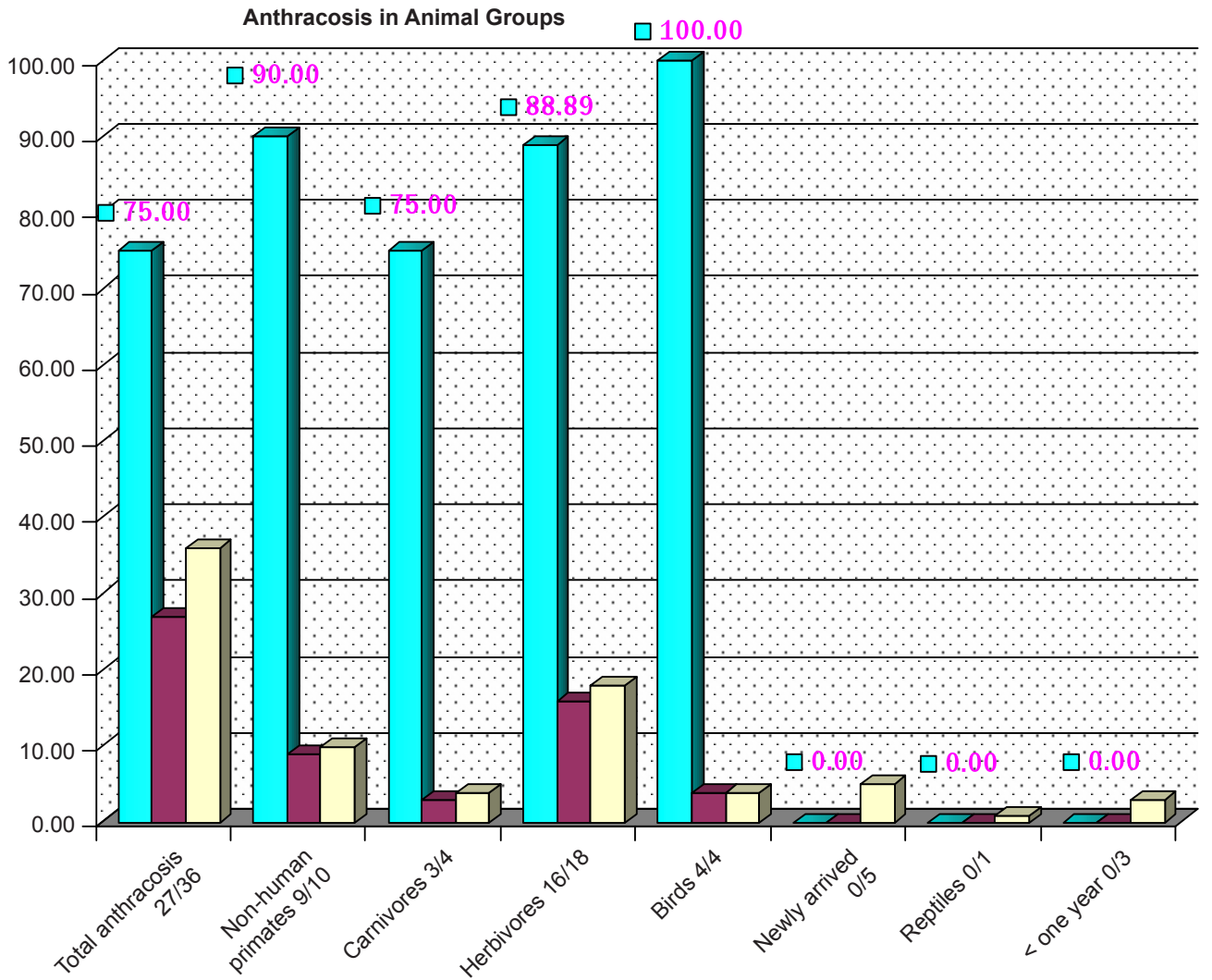

Figure 1. Percentages of Anthracosis

Domestic Animals. Vol. 3. , $4^{\text {th }}$ edition. Academic Press, UK, vii+223pp.

Luna, L. (1968). Manual of Histologic Staining Methods of the Armed Forces Institute of Pathology. New York, 110pp.

Manohar, B.M., A.V. Korandi, S. Vairamuthu, M.G. Jayathangaraj \& K. Senthilkumar (2006). Anthracosis in a Leaf Monkey (Presbytis pileatus). Tamilnadu Journal of Veterinary \& Animal Sciences 2(3): 112.

Runnels, R.A., W.S. Monlux \& A.W. Monlux (1960). Principles of Veterinary Pathology. $6^{\text {th }}$ edition. Lowa State University
Press, USA.

Selim, Z. (2008). Services in Traffic Police- Red Signal in Life by Ten Years of Service. The Daily Shamokal 29 August, 10pp. Sujatha, K., Ch. Srilatha \& S.N. Babu (2007). Pulmonary Anthracosis in Large Wild Felids. Zoos' Print Journal 22(11): 2902.

Yu-tong, Y., N.S. Wang, P.M. Rene \& S.P. Ronald (1983). Mineral Dusts in Lungs With Scar or Scar Cancer. Presented at the Meeting of the International Association of Pathologists, Atlanta, Georgia, 54: 1814-1823, 1984. 